\title{
A Cross-Site, Comparative Effectiveness Study of an Integrated HIV and Substance Use Treatment Program
}

\author{
Rae Jean Proeschold-Bell, Ph.D., Amy Heine, M.S.N., FNP-BC, ${ }^{2}$ Brian Wells Pence, Ph.D., M.P.H., ${ }^{3}$ \\ Keith McAdam, M.S.W., LCSW, ${ }^{4}$ and Evelyn Byrd Quinlivan, M.D.?
}

\begin{abstract}
Co-occurrence of HIV and substance abuse is associated with poor outcomes for HIV-related health and substance use. Integration of substance use and medical care holds promise for HIV patients, yet few integrated treatment models have been reported. Most of the reported models lack data on treatment outcomes in diverse settings. This study examined the substance use outcomes of an integrated treatment model for patients with both HIV and substance use at three different clinics. Sites differed by type and degree of integration, with one integrated academic medical center, one co-located academic medical center, and one co-located community health center. Participants $(n=286)$ received integrated substance use and HIV treatment for 12 months and were interviewed at 6-month intervals. We used linear generalized estimating equation regression analysis to examine changes in Addiction Severity Index (ASI) alcohol and drug severity scores. To test whether our treatment was differentially effective across sites, we compared a full model including site by time point interaction terms to a reduced model including only site fixed effects. Alcohol severity scores decreased significantly at 6 and 12 months. Drug severity scores decreased significantly at 12 months. Once baseline severity variation was incorporated into the model, there was no evidence of variation in alcohol or drug score changes by site. Substance use outcomes did not differ by age, gender, income, or race. This integrated treatment model offers an option for treating diverse patients with HIV and substance use in a variety of clinic settings. Studies with control groups are needed to confirm these findings.
\end{abstract}

\section{Introduction}

$\mathbf{S}$ TUDies OF HIV-INFECTED PATIENTS in care have reported varied rates of co-occurring substance use. These rates range from $15 \%$ of patients reporting drug and alcohol use in a consortium of $19 \mathrm{HIV}$ care sites, ${ }^{1}$ to $21 \%$ of patients in an HIV medical clinic meeting criteria for diagnosis of substance abuse, ${ }^{2}$ to $45 \%$ of a Washington HIV cohort who were diagnosed with a substance abuse disorder by psychiatrists. ${ }^{3}$ Despite the high prevalence, substance abuse (defined as meeting DSM-IV criteria for drug or alcohol dependence or abuse) and substance use (defined as any use of alcohol or illicit substances without regard to diagnostic criteria) remain undertreated in the HIV population. In a convenience sample of HIV patients receiving primary care, $71 \%$ of patients reported current or former substance use, yet only $24 \%$ reported receiving substance abuse treatment and less than half reported discussing substance use issues with their HIV pro- viders. ${ }^{4}$ Treatment of patients with HIV and substance abuse is complex, due to multiple levels of physical concerns and psychosocial and emotional needs. ${ }^{5-8}$ However, lack of treatment of substance use is related to worse adherence to antiretroviral therapy (ART), ${ }^{9-11}$ delayed initiation of ART, ${ }^{1,3}$ and increased risk of sexual transmission of HIV. ${ }^{12,13}$

Complex co-occurring health needs call for integrated care models. These models occur along a continuum where medical-behavioral provider communication ranges from coordinated care (offsite, some cross-provider communication), to co-located care (single site, enhanced cross-provider communication), to fully integrated care (single location, single treatment plan for patients) ${ }^{14}$ Integrated medicalmental health models are associated with improvements in mental illness diagnosis, stigma, and follow-up, ${ }^{15-17}$ and decreased alcohol use, as well as decreased mortality, if alcohol use affects the medical condition. ${ }^{18}$ Co-location of addiction treatment in primary care facilities was more effective than

\footnotetext{
${ }^{1}$ Center for Health Policy, Global Health Institute, ${ }^{3}$ Department of Community and Family Medicine, Global Health Institute, ${ }^{4}$ Department of Psychiatry, Duke University, Durham, North Carolina.

${ }^{2}$ Division of Infectious Diseases, Department of Medicine, University of North Carolina, Chapel Hill, North Carolina.
} 
coordinated care in a randomized controlled trial, when the addiction affected the outcome of the primary care complaint. $^{19}$

Integration of mental health, substance use, and HIV care has been recommended for this population. ${ }^{1,6,20-23}$ A handful of studies have examined the integration of HIV prevention and treatment into substance use programs, ${ }^{24,25}$ as well as integration of substance abuse assessment and interventions into HIV primary medical care. ${ }^{21,26}$ More recent work has highlighted provider characteristics and their role in the integration of routine alcohol assessment and brief interventions in the HIV clinic. ${ }^{27}$ Integration of HIV and opioid use disorder treatment programs has been proposed as an approach to address the challenges of pharmacological interventions in the presence of potential antiretroviral drug interactions. $^{28}$ Yet, clinic directors interested in adopting HIV-substance abuse care models need not only programmatic guidance but also effectiveness data under varied clinic environments and populations. Quality research on the effectiveness of co-located or integrated HIV-substance use treatment programs on substance use outcomes is needed.

We have developed a successful model of substance use treatment for HIV infected patients. ${ }^{20}$ To examine the effectiveness and replicability of this model of substance use treatment, we implemented the model in two additional locations (a community health center and an academic medical center). The modifications made at each site have been recently described. ${ }^{29}$ These sites differed in their degree of integrated treatment, size, and HIV population served. We hypothesized that a higher level of integrated care will have additional benefit above co-located care for those patients whose HIV and substance use create interrelated treatment issues. This study sought to answer the questions of: (1) did substance use outcomes differ based on level of integration and (2) did our specific HIV-substance use treatment model work equally well across varied sites? An effective model of substance use treatment that is easily integrated into a variety of HIV primary care locations will greatly enhance meeting the needs of HIV infected patients with untreated substance use.

\section{Methods}

\section{Recruitment and interviews}

HIV-positive patients with substance use disorders at three infectious disease clinics in North Carolina were recruited by clinician referral or through routine screening with the Substance Abuse and Mental Illness Symptoms Screener (SAMISS). ${ }^{30}$ The SAMISS has excellent sensitivity $(86 \%)$ and moderate specificity $(75 \%)$ for identifying HIV patients with active substance use disorders. ${ }^{31}$ Patients who screened positive for substance use met with an addictions specialist who discussed the study with them. To qualify, patients had to be HIV-positive, at least 18 years old, English-speaking, receiving medical care on site, and seeking substance use treatment or relapse prevention for any type or amount of substance. Private, in-person interviews lasted approximately 50-75 minutes and participants received \$20 (baseline) or \$15 (follow-up) compensation in gift cards. Three interviews were conducted by phone after patients relocated. The interviews focused on substance use, sexual behavior, and social context. The same items were asked at each time point except for stable demographic and historical substance use items. A total of 286 patients consented. The 6-month follow-up rate was $83 \%$ $(n=237)$ and the 12 -month was $68 \%(n=194)$. All procedures were approved by the Duke University Medical Center and the University of North Carolina Institutional Review Boards.

\section{Integrated treatment}

The integrated treatment has been described in-depth elsewhere, ${ }^{32}$ as has the implementation into the three study sites. ${ }^{29}$ Briefly, the treatment incorporated components found to be effective in non-HIV primary care and substance use integrated care, including assertive patient outreach and attention to the patient's social environment. ${ }^{33}$ Systems-level changes in the clinics involved co-locating addictions specialists in the HIV clinic and enhancing collaboration between medical and addictions providers. The addictions specialists provided flexible, patient-centered harm-reduction ${ }^{34}$ treatment through individual and/or group therapy for a 12-month period. Therapy content addressed HIV-specific issues such as ART side effects; substance use-specific issues such as triggers; and explicit links between HIV and substance use, such as adherence to ART. Motivational interviewing $(\mathrm{MI})^{35,36}$ and the transtheoretical model and stages of change $^{37}$ and Cognitive Behavioral Therapy techniques were used to: (1) assess readiness for behavior change and (2) advance behavior change. Assertive patient outreach and attention to the patient's social environment were key elements as well. ${ }^{33}$ At the more integrated site, addictions therapists provided treatment in the ID clinic, substance use screening was nearly universal, a single electronic medical record (EMR) was used, and weekly interdisciplinary team meetings were held to discuss patients. At the co-located sites, patient privacy rather than cross-provider communication was given more emphasis. Accordingly, group therapy was located away from the ID clinics and joint EMRs were not used. Also at the co-located sites, group therapy was held more often and meals were served to teach life skills. Sites also differed in size, with the community health center serving approximately 320 patients per year, compared to approximately 1400 patients per year served at the other sites.

\section{Measures}

Level of substance use was measured using the Addiction Severity Index (ASI) Lite, which has good reliability and validity. ${ }^{38-40}$ Separate alcohol and drug use scores were calculated using formulas in a National Institute on Drug Abuse (NIDA)-sponsored ASI scoring guide. ${ }^{41}$ Participants were asked their age, race, gender, income, and education status. They were asked whether they currently had an automobile available for use, whether they had ever injected drugs, and whether they had been incarcerated in the past 6 months. They were also asked about experiencing six psychological problems (serious depression; serious anxiety or tension; hallucinations; trouble understanding, concentrating, or remembering; trouble controlling violent behavior; and attempted suicide) in the past 30 days, followed by a single item on how "much have you been bothered by these psychological or emotional problems in the past 30 days" (not at all to extremely). For psychological problems, we used only this latter item about how much they had been bothered by all six problems combined. 


\section{Analyses}

Differences across sites and populations. To estimate the overall treatment response (change in alcohol and drug severity scores) over the 12-month project period, we modeled severity scores at baseline, 6, and 12 months, using linear generalized estimating equations (GEE) in STATA $10.0^{42}$ to allow for dependence within clusters due to the repeated-measures design. ${ }^{43}$ To test whether our treatment was equally or differentially effective across sites, we used likelihood ratio tests to compare a full model including site by time point interaction terms to a reduced model including only site fixed effects. To assess whether any observed differences in treatment response across sites could be explained by alternative factors, we then added as covariates variables that both differed significantly between sites and predicted treatment response in bivariate models, including interaction terms between time point and these covariates.

Attrition. To characterize the differences between those who did and did not complete follow-up surveys, we used logistic regression with the following variables to predict the presence of a 6-month or 12-month survey: baseline gender; education; age; Latino versus not Latino; African-American versus white; having an automobile available for use; ever injected drugs; income; incarcerated in the past 6 months; and mental health (how "bothered by psychological or emotional problems" in the past 30 days). Variables that were statistically significant in predicting the presence of either a 6- or 12-month survey were included as covariates in the final models.

\section{Results}

\section{Participants}

Participants were primarily African American (79.7\%) and white $(14.4 \%$ ) (Table 1$)$. Males comprised $62.2 \%$ of the sample. Average monthly incomes were low overall (\$777), but the range was quite wide $(\$ 0-\$ 10,592)$. Frequently used substances at baseline were alcohol $(50.7 \%)$, cocaine $(32.5 \%)$, and marijuana $(27.3 \%)$. Current heroin use was uncommon $(2.8 \%)$, although $26.2 \%$ of participants indicated that they had used injection drugs during their lifetime.

\section{Sites}

The three study sites have been previously described ${ }^{29}$ but briefly were a private academic clinic (\#1), an urban community health center (\#2) and a public academic clinic (\#3). Statistically significant site differences were present for income and percentage African American, uninsured, using cocaine at baseline, and ever injected drugs (Table 1). In addition, baseline ASI drug $(F=5.03, p=0.007)$ and alcohol $(F=5.73, p=0.004)$ severity scores significantly differed across sites.

\section{Attrition analyses}

Participants who endorsed higher levels at baseline of being bothered by psychological or emotional problems in the past 30 days were significantly more likely to have completed

Table 1. Demographic and Clinical Characteristics of Participants

\begin{tabular}{|c|c|c|c|c|}
\hline Characteristics & $\begin{array}{l}\text { Site 1: Private } \\
\text { Academic }\end{array}$ & $\begin{array}{l}\text { Site 2: Community } \\
\text { Health Center }\end{array}$ & $\begin{array}{l}\text { Site 3: Public } \\
\text { Academic }\end{array}$ & $\begin{array}{l}\text { All Sites } \\
\text { Combined }\end{array}$ \\
\hline Enrolled, N (Row \%) & $85(29.7 \%)$ & $91(31.8 \%)$ & $110(38.5 \%)$ & $286(100.0 \%)$ \\
\hline African-American, $\%$ & $74.1^{\mathrm{a}}$ & $90.1^{\mathrm{a}}$ & $75.2^{\mathrm{a}}$ & $79.7(n=227)$ \\
\hline$\%$ White & 18.8 & 3.3 & 20.2 & $14.4(n=41)$ \\
\hline$\%$ American Indian & 1.2 & 2.2 & 0.9 & $1.4(n=4)$ \\
\hline \% Native Hawaiian or Pacific Islander & 1.2 & 0 & 0 & $0.4(n=1)$ \\
\hline$\%$ Other & 0 & 1.1 & 0 & $0.4(n=1)$ \\
\hline$\%$ Multiple ethnicities & 4.7 & 3.3 & 3.7 & $3.9(n=11)$ \\
\hline$\%$ Hispanic & 3.6 & 2.2 & 3.7 & $3.2(n=9)$ \\
\hline$\%$ Female & 45.9 & 34.0 & 33.6 & $37.4(n=107)$ \\
\hline$\%$ Male & 52.9 & 65.9 & 66.4 & $62.2(n=178)$ \\
\hline$\%$ Transgender & 1.2 & 0 & 0 & $0.4(n=1)$ \\
\hline Age, mean (SD, range) & $44.8(7.0,29-67)$ & $42.2(7.5,22-62)$ & $42.9(7.5,22-59)$ & $43.3(7.4,22-67)$ \\
\hline Monthly income, mean (SD) & $\$ 1003^{\mathrm{a}}(\$ 1376)$ & $\$ 468^{\mathrm{a}}(\$ 413)$ & $\$ 862^{\mathrm{a}}(\$ 1313)$ & $\$ 777(\$ 1146)$ \\
\hline$\%$ uninsured & $22.4^{\mathrm{a}}$ & $53.9^{\mathrm{a}}$ & $25.7^{\mathrm{a}}$ & $33.7(n=96)$ \\
\hline \multicolumn{5}{|l|}{ Substance use at baseline, $\%(n)$ : } \\
\hline Cocaine/crack & $21.2^{\mathrm{a}}$ & $36.3^{\mathrm{a}}$ & $38.2^{\mathrm{a}}$ & $32.5(93)$ \\
\hline Alcohol & 47.1 & 55.0 & 50.0 & $50.7(145)$ \\
\hline Marijuana & 24.7 & 30.8 & 26.4 & $27.3(78)$ \\
\hline Heroin & 1.2 & 2.2 & 4.6 & $2.8(8)$ \\
\hline More than 1 substance & 30.6 & 40.7 & 35.4 & $35.6(102)$ \\
\hline$\%$ ever IDU & $20.0^{\mathrm{a}}$ & $22.0^{\mathrm{a}}$ & $34.6^{\mathrm{a}}$ & $26.2(75)$ \\
\hline Alcohol severity baseline score (mean, SD) & $0.0914^{\mathrm{a}}(0.0109)$ & $0.1513^{\mathrm{a}}(0.1557)$ & $0.1536^{\mathrm{a}}(0.1484)$ & $0.1340(0.1416)$ \\
\hline Drug severity baseline score (mean, SD) & $0.0582^{\mathrm{a}}(0.0691)$ & $0.0825^{\mathrm{a}}(0.0827)$ & $0.0942^{\mathrm{a}}(0.0822)$ & $0.0796(0.0798)$ \\
\hline $\begin{array}{l}\text { Bothered by emotions at baseline, } 1=\text { not } \\
\text { at all; } 5=\text { extremely (mean, SD) }\end{array}$ & $3.1(1.5)$ & $3.2(1.4)$ & $2.9(1.4)$ & $3.1(1.3)$ \\
\hline At baseline, have a car available for use & $24.7 \% \mathrm{o}^{\mathrm{a}}$ & $3.3 \%{ }^{\mathrm{a}}$ & $22.9 \%{ }^{\mathrm{a}}$ & $17.2 \%$ \\
\hline
\end{tabular}

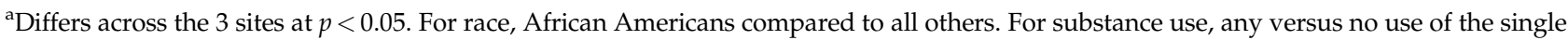
substance.

$\mathrm{SD}$, standard deviation; IDU, injection drug use. 
a 6-month interview (odds ratio $[\mathrm{OR}]=1.36$, confidence interval $[\mathrm{CI}]=1.03-1.79, p=0.03)$. This finding was not significant for completing a 12-month interview $(\mathrm{OR}=1.05$, $\mathrm{CI}=0.86-1.29, p=0.62)$. There was a trend toward significance of having completed a 12-month interview among participants who reported having an automobile for use at baseline $(\mathrm{OR}=2.04, \mathrm{CI}=0.97-4.29, p=0.06)$. This finding was not significant for completing a 6-month interview $(\mathrm{OR}=1.96, \mathrm{CI}=0.73-5.24, p=0.18)$. No other variables significantly predicted having completed either a 6- or 12-month interview, including severity of drug and alcohol use and treatment site.

\section{Demographic associations with change in ASI severity scores}

Change in ASI drug and alcohol severity scores were not significantly different by African American versus other race, age, gender, or income. For drug but not alcohol severity scores, scores differed by insurance status such that uninsured participants reported decreases in drug use sooner than insured participants $\left(\chi^{2}=7.62, p<0.05\right)$.

\section{Change in ASI severity scores over time}

For all sites combined, drug severity scores changed little from baseline to 6 months but decreased on average by 0.02 $(p<0.05)$ by 12 months (Table 2$)$. Alcohol severity scores decreased on average by 0.03 at 6 months and 0.04 by 12 months ( $p<0.05$ for both). When comparing models with and without site by time point interaction terms, there was no evidence of differences in drug score changes by site, but there was significant variation in crude alcohol score changes across sites $(p<0.05)$.

To investigate whether site differences in alcohol score changes could be explained by other factors, we fit adjusted models that controlled for variables that significantly differed across sites and were also significantly associated with either ASI alcohol or drug severity scores: (1) baseline severity scores and (2) insurance status (for drug scores only). These models also adjusted for variables identified through the attrition analysis (use of a car and psychological problems). Adjusted changes were similar to the unadjusted changes at 6 and 12 months. When interaction terms for baseline severity score by time point were included, there was evidence of significant variation in score changes by baseline severity $(p<0.05$ for both alcohol and drug ASI scores). Once variation by baseline severity was incorporated into the model, there was no remaining evidence of variation in score changes by site.

To illustrate the variation in score changes by baseline severity, we graphically present the trajectory of severity scores over time for individuals with low, medium, and high baseline severity (Figs. 1 and 2 showing alcohol and drug scores, respectively). Predicted scores at each time point were calculated from the final multivariable model adjusting for predictors of attrition, site, and baseline severity, and incorporating interaction terms between baseline severity and time point. Since baseline drug and alcohol severity scores were modeled as continuous variables, for illustrative purposes we present predicted trajectories for hypothetical individuals at the 10th, 50th, and 90th percentiles of baseline drug or alcohol severity. For both alcohol and drug scores, the greatest decreases were predicted to be by a participant with high $\left(90^{\text {th }}\right.$ percentile) baseline use, with statistically significant decreases predicted between 0 and 6 months and between 0 and 12 months. For a participant whose baseline use was at the median, for both alcohol and drug scores there was a significant predicted decrease between 0 and 12 months but not between 0 and 6 months. For a participant whose baseline use was low (10th percentile), for both alcohol and drug scores there was a significant predicted increase between 0 and 6 months and between 0 and 12 months.

\section{Sensitivity analyses: drug use}

ASI drug scores were examined separately for participants reporting use of cocaine, heroin, and marijuana, and participants who never reported using any alcohol at any time point. For cocaine and marijuana users, as well as never-alcohol users, 6-month change in drug use was not significant but 12month change in drug use was significant. There were too few heroin user observations (30 observations for paired time points) for adequate statistical power, but the pattern was the same with mean drug use similar between baseline and 6 months, with a decrease at 12 months.

\section{Discussion}

Addiction severity for both alcohol and drug use decreased in the integrated as well as the co-located treatment sites for patients with co-occurring HIV and substance abuse. Decreases in alcohol and drug addiction severity were similar

Table 2. ASI Alcohol and Drug Mean (SD) Baseline Scores and Unadjusted and Adjusted Change FROM BASELINE 6 AND 12 MONTHS

\begin{tabular}{|c|c|c|c|c|c|c|c|c|}
\hline & \multirow[b]{2}{*}{$\begin{array}{l}\text { Baseline } \\
(\mathrm{n}=281)\end{array}$} & \multicolumn{3}{|c|}{ Unadjusted } & \multicolumn{4}{|c|}{ Adjusted } \\
\hline & & $\begin{array}{l}\text { Change at } \\
6 \text { months } \\
(\mathrm{n}=235)\end{array}$ & $\begin{array}{l}\text { Change at } \\
12 \text { months } \\
(\mathrm{n}=193)\end{array}$ & $\begin{array}{l}\mathrm{p} \text { Value for } \\
\text { difference } \\
\text { across sites }\end{array}$ & $\begin{array}{l}\text { Change at } \\
6 \text { months } \\
(\mathrm{n}=235)\end{array}$ & $\begin{array}{l}\text { Change at } \\
12 \text { months } \\
(\mathrm{n}=193)\end{array}$ & $\begin{array}{c}\mathrm{p} \text { Value for } \\
\text { difference by } \\
\text { baseline ASI score }\end{array}$ & $\begin{array}{l}\mathrm{p} \text { Value for } \\
\text { difference } \\
\text { across sites }\end{array}$ \\
\hline Drug score & $0.0796(0.0798)$ & -0.0013 & $-0.0227^{\mathrm{a}}$ & 0.48 & -0.0007 & $-0.0236^{\mathrm{a}}$ & $<0.01$ & 0.94 \\
\hline Alcohol score & $0.1340(0.1416)$ & $-0.0328^{a}$ & $-0.0416^{\mathrm{a}}$ & $<0.01$ & $-0.0332^{\mathrm{a}}$ & $-0.0458^{\mathrm{a}}$ & $<0.01$ & 0.43 \\
\hline
\end{tabular}

${ }^{a} p<0.05$ for mean difference from baseline. $p$ values for differences across sites computed as likelihood ratio tests comparing models with (full) and without (reduced) site by time point interaction terms.

Scores adjusted for baseline alcohol or drug scores, having an automobile available at baseline, and reporting psychological problems at baseline. Drug scores are also adjusted for baseline insurance status.

ASI, Addiction Seventy Index; SD, standard deviation. 
FIG. 1. Predicted Addiction Severity Index (ASI) alcohol score means at 0, 6, and 12 months for a hypothetical participant with a baseline alcohol severity score at the 10th, 50th, and 90th percentile. *Significant difference from baseline. (Color image can be found at www.liebertonline .com/apc).

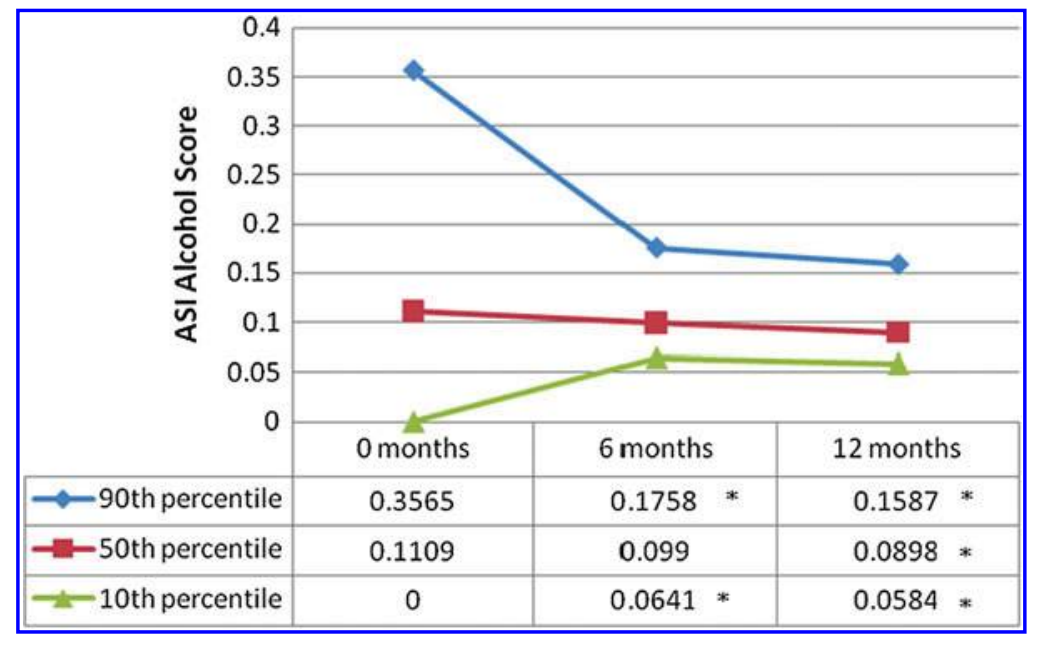

across gender, age, and income levels. Decreases in alcohol and drug composite scores were also similar across race. A treatment that works well across groups and sites is desirable for applicability to HIV medical care clinics. Effective treatment for African American patients is especially important given the growing HIV epidemic among African-Americans. In $2005,49 \%$ of new HIV diagnoses were among African Americans, even though they only comprised $12 \%$ of the U.S. population. $^{44}$

Decreases in alcohol and drug addiction severity did not significantly differ by site, despite recognizable differences in clinic populations and treatment adaptations. ${ }^{29}$ It may be that co-location is sufficiently integrated for effective HIVsubstance abuse treatment. As noted previously, co-located care has been found to be more effective than coordinated care for dually diagnosed patients whose addiction affects their comorbidity. ${ }^{19}$ However, integrated and co-located models have not been previously compared for substance use treatment of HIV infected patients.

Low substance use severity at baseline was predictive of increased addiction severity at 6 and 12 months. It is possible that the treatment was not successful for participants entering with low severity scores. The program included an extensive outreach period with an addictions specialist and substance use may have decreased prior to study enrollment. Some participants enrolled specifically to prevent relapse. This observation suggests the need for additional or more comprehensive aftercare with a focus on relapse prevention. Alternatively, perhaps we should have matched patients with low severity to a less intensive outpatient treatment, as is recommended by the American Society of Addiction Medicine. ${ }^{45}$ Regardless, it is important to note that even after the increase, the 12-month follow-up scores were below the scores for patients at the 50th and 90th percentiles of baseline use; the scores continued to reflect a low addiction severity throughout the follow-up period.

The integrated HIV-substance abuse intervention examined in this study was based in large part on a previous HIVsubstance abuse-mental illness intervention by Whetten and colleagues. $^{20}$ These studies differed in that the current study did not require that participants qualify for a mental illness diagnosis, and the current study had a higher level of integrated care (co-located or integrated versus coordinated care). Unlike Whetten and colleagues, we did not find a decrease in ASI drug scores between 0 and 6 months, possibly because our drug scores were lower at baseline. Both studies found significant decreases in ASI alcohol scores between 0 and 6 months, and between 0 and 12 months, as well as ASI drug scores decreases between 0 and 12 months. Despite the differences in the two studies, severity of addiction was
FIG. 2. Predicted Addiction Severity Index (ASI) drug use means at 0, 6, and 12 months for a hypothetical participant with a baseline drug use score at the 10th, 50th, and 90th percentile. *Significant difference from baseline. (Color image can be found at www.liebertonline .com/apc).

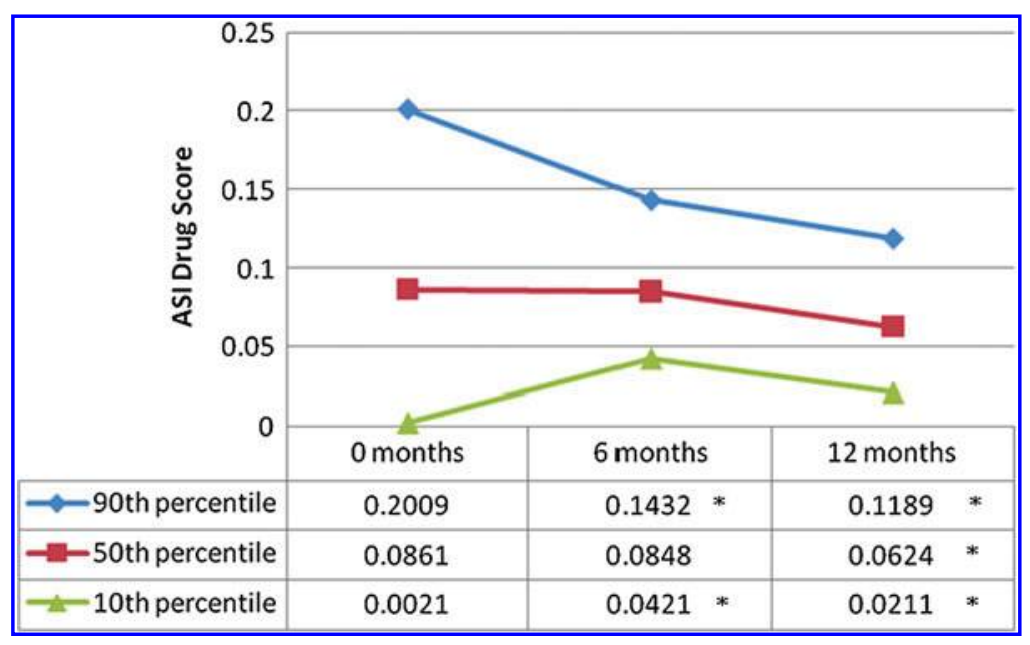


consistently reduced. The decreases in severity scores in our study and Whetten and colleagues' were modest in comparison to those of other behavioral treatments, such as in the Cocaine Collaborative Treatment Study. ${ }^{46}$ It is possible that our results were attenuated by the HIV and mental health comorbidities faced by our treatment population.

To date, studies for persons with HIV and substance use have focused on subgroups of HIV-positive substance users. Specifically, for alcohol use, a randomized study contrasting eight-session treatment conditions of health education versus motivational interviewing (MI) combined with cognitivebehavioral therapy found less alcohol use for both conditions. Another intervention specifically for MSM used an eightsession intervention based on MI and the Transtheoretical Model to decrease alcohol use. ${ }^{47}$ A case management intervention with 18 individual sessions for HIV-positive youth found decreases in substance use over time. ${ }^{48}$ In yet another intervention, the Healthy Living Project did not focus on substance use but rather on coping with stressors for HIVpositive MSM engaging in high-risk sexual activity. ${ }^{49}$ Among its results, however, were decreases in alcohol use and some kinds of drug use. Finally, a group therapy treatment for HIV-positive gay or bisexual men found reductions in drug use. $^{50}$

This study's findings are limited by the use of a pre-postpost design without a comparison group, reducing our ability to make causal inferences and also precluding us from ruling out regression to the mean. Because we recruited current substance users, it is possible that extremely high initial substance use scores would have decreased at future assessment points even without intervention. Future evaluation of the intervention using more rigorous study designs is needed. Another limitation is the follow-up interview rates. Statistical models controlled for relevant differences between those who did and did not complete follow-up interviews. Nevertheless, it is possible that participants with worse or escalating substance use did not complete follow-up interviews. Social desirability and recall bias may have influenced self-reported substance use. To minimize this, participants were told before each interview that they had a 1 in 10 chance of being asked to provide a urine sample for toxicology. However, participants' self-reported data were not verified against urine analysis results.

Finally, we must note that this study's treatment is complex to implement. System-level changes must be used to implement communication between medical providers and addictions specialists. These changes require adequate time and commitment to four principles: a shared vision of the biopsychosocial model of care; the behavioral health provider as an integral part of the medical team; psychological and biomedical complications on equal footing in regards to patient morbidity; and the mental health provider's adaptation to the medical setting. ${ }^{51,52}$

The treatment tested here differs from other treatments in its use of co-locating addictions therapists, its relatively long duration, its broad inclusion criteria, and its focus on substance abuse. This study contributes an intervention to the options for clinic directors seeking to adopt mental health and/or HIV-substance use treatments. The benefit of choosing the treatment presented here is that it has been tested with real-life clinic adaptations and with patients who vary in insurance status, income level, gender, and age, as well as African American and white races.
Areas of future research on this treatment model to address causality include using a randomized clinical trial design or an interrupted time series design, along with developing methods for earlier enrollment to capture the effects of the prolonged outreach phase of the program. In addition, shorter integrated HIV-substance use interventions are likely needed because not all patients with HIV and substance use are willing to engage in a 12-month treatment program. The need for long-term, relapse prevention resources is also evident. Given the challenges of treating patients afflicted with both HIV and substance use, models of integrated HIV and substance use care must continue to be designed creatively and tested comprehensively. Likewise, HIV clinic directors must be creative, thoughtful, and dedicated in their choices of treatment options for their patients.

\section{Acknowledgments}

This work was supported by the Substance Abuse and Mental Health Services Administration (SAMHSA) HIV / TCE grant number 6H79TI14386. We thank the addictions specialists Stephanie Bouis, Janet Scovil, Andrea Murray, Laura Musselwhite, and Katie Cooper, as well as the many medical providers who worked with them, without whom this study would not have been possible. We also thank Douglas Thomas and Melissa Green for overseeing data collection. Finally, we want to acknowledge the support of Kathryn Whetten, as mentor, guide, and advisor in the adapted treatment model upon which this manuscript is based.

\section{Author Disclosure Statement}

No competing financial interests exist.

\section{References}

1. Chander G, Himelhoch S, Fleishman JA, et al. HAART receipt and viral suppression among HIV-infected patients with co-occurring mental illness and illicit drug use. AIDS Care 2009;21:655-663.

2. Pence BW, Miller WC, Whetten K, et al. Prevalence of DSMIV-defined mood, anxiety, and substance use disorders in an HIV clinic in the Southeastern United States. J Acquir Immune Defic Syndr 2006;42:298-306.

3. Tegger MK, Crane HM, Tapia KA, et al. The effect of mental illness, substance use, and treatment for depression on the initiation of highly active antiretroviral therapy among HIVinfected individuals. AIDS Patient Care STDs 2008;22: 233-243.

4. Korthuis PT, Josephs JS, Fleishman JA, et al. Substance abuse treatment in human immunodeficiency virus: The role of patient-provider discussions. J Subst Abuse Treat 2008;35: 294-303.

5. Douaihy AB, Jou RJ, Gorske $\mathrm{T}$, et al. Triple diagnosis: dual diagnosis and HIV disease part 2. AIDS Read 2003;13: 375-382.

6. Nijhawan A, Kim S, Rich JD. Management of HIV infection in patients with substance use problems. Curr Infect Dis Rep 2008; 10:432-438.

7. Soto TA, Bell J, Pillen MB, et al. Literature on integrated HIV care: A review. AIDS Care 2004;16(Suppl 1):S43-55.

8. Douaihy AB, Jou RJ, Gorske $\mathrm{T}$, et al. Triple diagnosis: dual diagnosis and HIV disease part 1. AIDS Read 2003;13: 331-341. 
9. Mugavero M, Ostermann J, Whetten $K$, et al. Barriers to antiretroviral adherence: The importance of depression, abuse, and other traumatic events. AIDS Patient Care STDs 2006;20:418-428.

10. Hicks PL, Mulvey KP, Chander G, et al. The impact of illicit drug use and substance abuse treatment on adherence to HAART. AIDS Care 2007;19:1134-1140.

11. Tucker JS, Burnam MA, Sherborne CD, et al. Substance-use and mental health correlates of nonadherence to antiretroviral medications in a sample of patient with human immunodifficiency virus infection. Am J Med 2003;114: 573-580.

12. Beckett M, Burnam A, Collins RL, et al. Substance use and high risk sex among people with HIV: A comparison across exposure groups. AIDS Behav 2003;7:209-219.

13. Drumright LN, Strathdee SA, Little SJ, et al. Unprotected anal intercourse and substance use before and after HIV diagnosis among recently HIV-infected men who have sex with men. Sex Transm Dis 2007;34:401-407.

14. Blount A. Integrated primary care: Organizing the evidence. Fam Syst Health 2003;21:121-132.

15. Bartels SJ, Coakley EH, Zubritsky C, et al. Improving access to geriatric mental health services: A randomized trial comparing treatment engagement with integrated versus enhanced referral care for depression, anxiety, and at-risk alcohol use. Am J Psychiatry 2004;161:1455-1462.

16. Krahn D, Bartels SJ, Coakley EH, et al. PRISM-E: Comparison of integrated care and enhanced specialty referral models in depression outcomes. Psychiatr Serv 2006;57:946-953.

17. Williams J, Shore S, Meschan J. Co-location of mental health professionals in primary care settings: Three North Carolina models. Clin Pediatr 2006;45:537-543.

18. Willenbring ML. Integrating care for patients with infectious, psychiatric, and substance use disorders: Concepts and approaches. AIDS 2005;19:S227-S237.

19. Weisner C, Mertens J, Parthasarathy S, et al. Integrating primary medical care with addiction treatment: A randomized controlled trial. JAMA 2001;286:1715-1723.

20. Whetten $K$, Reif $S$, Ostermann J, et al. Improving health outcomes among individuals with HIV, mental illness, and substance use disorders in the Southeast. AIDS Care 2006;18(Suppl 1):S18-S26.

21. Zaller N, Gillani FS, Rich JD. A model of integrated primary care for HIV-positive patients with underlying substance use and mental illness. AIDS Care 2007;19:1128-1133.

22. Weaver MR, Conover CJ, Proescholdbell RJ, et al. Utilization of mental health and substance abuse care for people living with HIV / AIDS, chronic mental illness, and substance abuse disorders. J Acquir Immune Defic Syndr 2008;47:449-458.

23. Celentano D, Lucas G. Optimizing treatment outcomes in HIV-infected patients with substance abuse issues. $\underline{\text { Clin }}$ Infect Dis 2007;45:S318-S323.

24. Lucas GM, Mullen BA, Weidle PJ, et al. Directly administered antiretroviral therapy in methadone clinics is associated with improved HIV treatment outcomes, compared with outcomes among concurrent comparison groups. Clin Infect Dis 2006;42:1628-1635.

25. Rothman J, Rudnick D, Slifer M, et al. Co-located substance use treatment and HIV prevention and primary care services, New York State, 1990-1992: A model for effective service delivery to a high-risk population. J Urban Health 2007;84:226-242.

26. Winiarski MG, Beckett E, Salcedo J. Outcomes of an innercity HIV mental health programme integrated with primary care and emphasizing cultural responsiveness. AIDS Care 2005;17:747-756.

27. Strauss S, Tiburcio NJ, Munoz-Plaza C, et al. HIV care providers' implementation of routine alcohol reduction support for their patients. AIDS Patient Care STDs 2009;23: 211-218.

28. Batkis M, Treisman GJ, Angelino AF. Integrated opioid use disorder and HIV treatment: Rationale, clinical guidelines for addiction treatment, and review of interactions of antiretroviral agents and opioid agonist therapies. AIDS Patient Care STDs 2010;24:15-22.

29. Lombard F, Proescholdbell RJ, Cooper K, et al. Adaptations across clinical sites of an integrated treatment model for persons with HIV and substance abuse. AIDS Patient Care STDs 2009;23:631-638.

30. Whetten K, Reif S, Swartz M, et al. A brief mental health and substance abuse screener for persons with HIV. AIDS Patient Care STDs 2005;19:89-99.

31. Pence BW, Gaynes BN, Whetten K, et al. Validation of a brief screening instrument for substance abuse and mental illness in HIV-positive patients. I Acquir Immune Defic Syndr 2005;40:434-444.

32. Bouis $S$, Reif $S$, Whetten $K$, et al. An integrated, multidimensional treatment model for individuals living with HIV, mental illness, and substance abuse. Health Soc Work 2007; 32:268-278.

33. Drake RE, Essock SM, Shaner A, et al. Implementing dual diagnosis services for clients with severe mental illness. Psychiatr Serv 2001;52:469-476.

34. Bigg D. Substance use management: A harm reductionprincipled approach to assisting the relief of drug-related problems. J Psychoactive Drugs 2001;33:33-38.

35. Miller MR. Motivational interviewing: Research, practice and puzzles. Addict Behav 1996;21:835-842.

36. Miller WR. Motivational interviewing with problem drinkers. Behav Psychcother 1983;11:147-172.

37. Prochaska JO, DiClemente CC. Toward a comprehensive model of change. In Miller WR, Heather N, eds. Treating Addictive Behaviors: Processes of Change. New York: Plenum Press, 1986:3-27.

38. McLellan AT, Kushner H, Metzger D, et al. The Fifth Edition of the Addiction Severity Index. I Subst Abuse Treat 1992; 9:199-213.

39. Leonhard C, Mulvey K, Gastfriend DR, et al. The Addiction Severity Index: A field study of internal consistency and validity. I Subst Abuse Treat 2000;18:129-135.

40. Zanis DA, McLellan AT, Cnaan RA, et al. Reliability and validity of the Addiction Severity Index with a homeless sample. I Subst Abuse Treat 1994;11:541-548.

41. McGahan PL, Griffith JA, Parente R, et al. Addiction Severity Index composite scores manual 1986. www.tresearch.org/ resources/compscores/CompositeManual.pdf (Last accessed July 28, 2010).

42. StataCorp. Stata Statistical Software: Release 10.0. College Station, TX: StataCorp LP 2007.

43. Zorn C. Generalized estimating equation models for correlated data: A review with applications. American Journal of Political Science. 2001;45:470-490.

44. Centers_for_Disease_Control_and_Prevention. HIV/AIDS and African Americans 2007. www.cdc.gov/hiv/topics/aa/ index.htm (Last accessed July 28, 2010).

45. Mee-Lee D, Shulman GD, Fishman M, et al. ASAM Patient Placement Criteria for the Treatment of SubstanceRelated Disorders, Second Edition-Revised (ASAM 
PPC-2R). American Society of Addiction Medicine, Inc., 2001.

46. Crits-Christoph P, Siqueland L, Blaine J, et al. Psychosocial treatments for cocaine dependence: National Institute on Drug Abuse Collaborative Cocaine Treatment Study. Arch Gen Psychiatry 1999;56:493-502.

47. Velasquez MM, vonSternberg K, Johnson DH, et al. Reducing sexual risk behaviors and alcohol use among HIVpositive men who have sex with men: A randomized clinical trial. J Consult Clin Psychol 2009;77:657-667.

48. Comulada WS, Weiss RE, Cumberland W, et al. Reductions in drug use among young people living with HIV. Am J Drug Alcohol Abuse 2007;33:493-501.

49. Wong FL, Rotheram-Borus J, Lightfoot M, et al. Effects of behavioral intervention on substance use among people living with HIV: The Healthy Living Project randomized controlled study. Addiction 2008;103:1206-1214.
50. Shoptaw S, Reback CJ, Larkins S, et al. Outcomes using two tailored behavioral treatments for substance abuse in urban gay and bisexual men. J Subst Abuse Treat 2008;35:285-293.

51. Lehman WEK, Greener JM, Simpson DD. Assessing organizational readiness for change. I Subst Abuse Treat 2002; 22:197-209.

52. Davis TF. From pilot to mainstream: Promoting collaboration between mental health and medicine. Families Syst Health 2001;19:37-45.

Address correspondence to: Rae Jean Proeschold-Bell, Ph.D. Duke Global Health Institute Duke University Center for Health Policy Box 90392, Durham, NC 27708

E-mail: Rae.Jean@duke.edu 
This article has been cited by:

1. Rae Jean Proeschold-Bell, Bettina Hoeppner, Baishakhi Taylor, Sarah Cohen, Rachel Blouin, Beth Stringfield, Andrew J. Muir. 2010. An Interrupted Time Series Evaluation of a Hepatitis C Intervention for Persons with HIV. AIDS and Behavior . [CrossRef] 